\title{
HOMOLYTIC REACTIONS OF ORGANOBORANES
}

\author{
Alwyn G. Davies \\ Chemistry Department, University College London, \\ 20 Gordon Street, London WC1H OAJ, UK
}

\begin{abstract}
Organoboranes readily undergo bimolecular homolytic substitution at the boron centre according to the equation:

$$
\begin{gathered}
\mathrm{X} \cdot+\mathrm{B}-\mathrm{R} \rightarrow \mathrm{X}-\mathrm{B}-+\mathrm{R} \cdot \\
\left(\mathrm{X}=\mathrm{ROO} \cdot \mathrm{RO} \cdot \mathrm{RS} \cdot \mathrm{R}_{2} \mathrm{~N} \cdot, \mathrm{R}_{2} \mathrm{CO}^{\mathrm{T}} \mathrm{etc} .\right)
\end{gathered}
$$

Rate constants for a number of these reactions have been determined, and interpreted in terms of electronic and steric effects.
\end{abstract}

\section{INTRODUCTION}

Whereas nucleophiles (e.g. equation 1) and electrophiles (e.g. equation 2) react readily at saturated carbon centres, free radical reagents normally react at the peripheral monovalent (hydrogen or halogen) atoms of saturated organic compounds (e.g. equations 3 and 4).

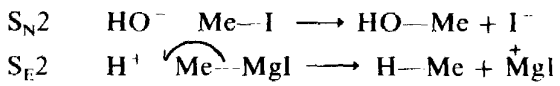

$$
\begin{aligned}
& \mathrm{S}_{\mathrm{H}^{2}} \mathrm{Bu}^{\mathrm{t}} \mathrm{O} \cdot{ }^{2} \\
& \mathrm{Me} \cap \sqrt{\mathrm{Cl}} \mathrm{CCl}_{3} \longrightarrow \mathrm{MeCl}+\cdot \mathrm{CCl}_{3}
\end{aligned}
$$

This imposed a major restriction on the type of homolytic reactions which could be studied, and the constitutional and stereochemical methods which could be used to investigate their mechanisms. As a consequence, the factors which govern heterolytic reactivity are much better understood than those which determine homolytic reactivity.

Although it remains true that no unambiguous $\mathrm{S}_{\mathrm{H}} 2$ reaction at a saturated carbon atom under simple conditions has been established, it has been shown in recent years that $S_{\mathrm{H}} 2$ reactions do occur, often extremely rapidly, at multivalent metal centres (equation 5$)^{1,2}$.

$$
\begin{aligned}
& \left(\mathrm{X}=\mathrm{ROO} \cdot \mathrm{RO} \cdot \mathrm{RS} \cdot \mathrm{R}{ }_{2} \mathrm{~N} \cdot \mathrm{RSO} \cdot \mathrm{R}, \mathrm{R}_{2} \mathrm{CO}^{\mathrm{T}}\right. \text { etc. } \\
& \mathrm{M}=\mathrm{Li}, \mathrm{Mg}, \mathrm{Zn}, \mathrm{Cd}, \mathrm{B}, \mathrm{Al}, \mathrm{TI}, \mathrm{Si}, \mathrm{Sn}, \mathrm{P}, \mathrm{As}, \mathrm{Sb}, \mathrm{Bi}, \text { etc. })
\end{aligned}
$$




\section{ALWYN G. DAVIES}

Recognition of this has made it possible to interpret the mechanism of some familiar organometallic reactions and to predict novel ones, but, of more fundamental importance, it has provided a wide new context within which the behaviour of free radicals can be investigated.

The metallic compounds which have been studied most thoroughly as yet are those of boron, tin and phosphorus. The organoboranes exhibit the most straightforward behaviour and are discussed here. The reactions which occur, and the methods by which their mechanisms and kinetics have been studied, are presented first, and then the kinetic results are interpreted in terms of polar and steric effects.

\section{ALKYLPEROXYL RADICALS}

The $\mathrm{S}_{\mathrm{H}} 2$ mechanism at a boron centre was proposed by D. S. Matteson in $1964^{3}$, but was first clearly established in 1966 in the autoxidation of organoboranes ${ }^{4}$.

In dilute solution, alkylboranes react with oxygen, often very rapidly, to give alkylperoxyboranes ${ }^{5}$. Largely because the common inhibitors of radical processes had no effect on these reactions, it was proposed that these and other organometallic autoxidations followed a heterolytic mechanism ${ }^{6,8}$.

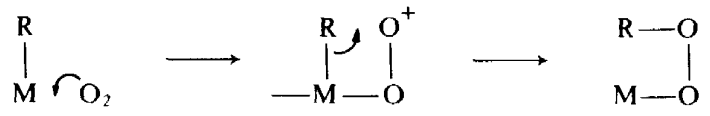

The resolution, in 1965, of 1-phenylethylboronic acid ${ }^{9}$ allowed this mechanism to be tested; it was shown that the peroxide was formed with complete racemization of the 1-phenylethyl group (equation 7$)^{4}$ and that this autoxidation ${ }^{4}$, and that of many other organometallic compounds ${ }^{10}$, could be inhibited by powerful radical scavengers such as galvinoxyl.

$$
\begin{array}{rcc} 
& \mathrm{PhCH}(\mathrm{Me}) \mathrm{B}(\mathrm{OH})_{2}+\mathrm{O}_{2} \rightarrow \mathrm{PhCH}(\mathrm{Me}) \mathrm{OOB}(\mathrm{OH})_{2} \\
{[x]_{\mathrm{D}}} & -15.1^{\circ} \text { (in benzene) } & 0.0^{\prime}
\end{array}
$$

It appeared then that the mechanism of autoxidation of an organometallic compound was similar to that of a hydrocarbon (equations 8-11); in this context, as in so many others, hydrogen behaves as just another metal.

Initiation

$$
\begin{aligned}
R & \rightarrow \mathrm{R} \cdot \\
\mathrm{R} \cdot+\mathrm{O}_{2} & \rightarrow \mathrm{ROO} \cdot
\end{aligned}
$$

Propagation

$$
\mathrm{ROO} \cdot+\mathrm{MR} \stackrel{k_{\mathrm{p}}}{\rightarrow} \mathrm{ROOM}+\mathrm{R} \cdot
$$

Termination

$$
2 \text { ROO. } \stackrel{2 k_{1}}{\rightarrow} \text { products }
$$

This process should obey the same rate law as that which governs the autoxidation of a hydrocarbon (equations $8-11, M=H$ ), i.e.

$$
-\mathrm{d}\left[\mathrm{O}_{2}\right] / \mathrm{d} t=k_{\mathrm{p}}[\mathrm{MR}]\left(R_{\mathrm{i}} / 2 k_{\mathrm{t}}\right)^{\frac{1}{2}}
$$


This was confirmed by $K$. U. Ingold ${ }^{11}$, who was able to determine the value of $k_{\mathrm{p}}$, the rate constant for the $\mathrm{S}_{\mathrm{H}} 2$ reaction of the alkylperoxyl radical at the boron centre, for a variety of organoboranes. Typically, whereas the value for $k_{\mathrm{p}}$ for the attack at hydrogen in toluene at $30^{\circ}$ is $0.26 \mathrm{M}^{-1} \mathrm{~s}^{-1}$, that for the attack at boron in tributylborane is $2 \times 10^{6} \mathrm{M}^{-1} \mathrm{~s}^{-1}$. The failure of the inhibitors which had been used in the early studies was due simply to the fact that they could not compete with the very reactive boranes for reaction with the alkylperoxyl radicals.

We realized that there must be a wide field of homolytic organometallic reactions which was ripe for exploration.

\section{ALKOXYL RADICALS}

Alkoxyl radicals are usually more reactive towards hydrocarbons than are alkylperoxyl radicals; one would expect then that alkoxyl radicals should also take part in an $\mathrm{S}_{\mathrm{H}} 2$ reaction at a boron centre. This was established by photolysing di-t-butyl peroxide or di-t-butyl hyponitrite in the presence of organoboranes in an e.s.r. cavity, when the spectrum of the displaced alkyl radical can be observed, e.g. (cf. refs 12,13 )

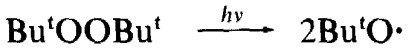

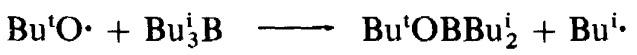

If the reaction is carried out in the presence of cyclopentane, the relative intensities of the spectra of the cyclopentyl and alkyl radicals are a measure of the relative reactivities of the cyclopentane and alkylborane, and as the absolute rate constant for the first reaction is known, that for the second can be determined ${ }^{14}$.

$$
\begin{aligned}
& \mathrm{Bu}^{\mathrm{t} O} \cdot \underbrace{\mathrm{C}_{5} \mathrm{H}_{10}}_{\frac{\mathrm{BR}_{3}}{k_{\mathrm{B}}}} \mathrm{Bu}^{\mathrm{t}} \mathrm{OBB} \mathrm{OH}+\mathrm{C}_{5} \mathrm{H}_{9} \cdot \\
& k_{\mathrm{B}} / k_{\mathrm{H}}=[\mathrm{R} \cdot]\left[\mathrm{C}_{5} \mathrm{H}_{10}\right] /\left[\mathrm{C}_{5} \mathrm{H}_{9} \cdot\right]\left[\mathrm{BR}_{3}\right]
\end{aligned}
$$

If the source of the alkoxyl radical is a hypochlorite, the displaced alkyl radical regenerates the alkoxyl radical by reaction (16), and a chain process is established.

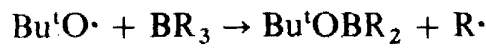

$$
\begin{aligned}
& \mathrm{R} \cdot+\mathrm{ClOBu}^{\mathrm{t}} \rightarrow \mathrm{RCl}+\cdot \mathrm{OBu}^{\mathrm{t}}
\end{aligned}
$$

If the organoborane is caused to compete with an alkane for reaction with the alkoxyl radical, the relative yields of alkyl chloride derived from the borane and from the alkane give a measure of their relative reactivities, and if the rate constant for the latter reaction is known, that for reaction (15) can again be determined ${ }^{15}$.

An alternative way in which a chain reaction can be established is by causing the alkylborane to react with formaldehyde, or with an unsaturated 
carbonyl compound or epoxide or a quinone (e.g. equations 17-19), and these reactions may be useful in synthesis ${ }^{16}$.

$$
\mathrm{R} \cdot+\mathrm{CH}_{2}=\mathrm{O} \longrightarrow \mathrm{RCH}_{2} \dot{\mathrm{O}} \stackrel{\mathrm{BR}_{3}}{\longrightarrow} \mathrm{RCH}_{2} \mathrm{OBR}_{2}+\mathrm{R} \cdot
$$

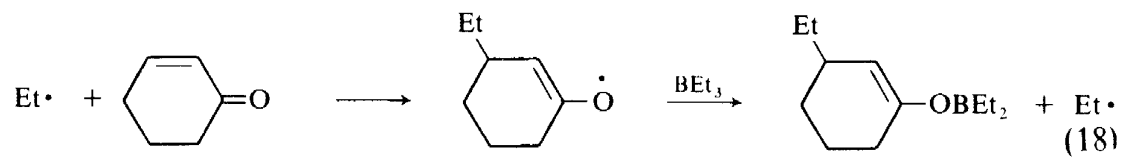

$$
\begin{aligned}
\mathrm{Et} \cdot & +\mathrm{CH}_{2}=\mathrm{CH}-\mathrm{C}{ }_{\mathrm{O}}^{\mathrm{CH}}-\mathrm{CH}_{2} \rightarrow \mathrm{EtCH}_{2} \mathrm{CH}=\mathrm{CHCH}_{2} \mathrm{O} \\
& -\mathrm{BEt}_{3}-\mathrm{EtCH}_{2} \mathrm{CH}=\mathrm{CHCH}_{2} \mathrm{OBEt}_{2}
\end{aligned}
$$

\section{ALKYLTHIYL RADICALS}

If di-t-butyl disulphide is photolysed in the presence of an organoborane, reactions (20) and (21) occur (cf. reactions 12 and 13), and the e.s.r. spectrum of the displaced alkyl radical, $R \cdot$, can be observed ${ }^{17}$.

$$
\begin{aligned}
& \mathrm{Bu}^{t} \mathrm{SSBu}^{\mathrm{t}} \stackrel{h}{\longrightarrow} 2 \mathrm{Bu}^{\mathrm{t}} \mathrm{S} \cdot \\
& \mathrm{Bu}^{\mathrm{t}} \mathrm{S} \cdot+\mathrm{BR}_{3} \longrightarrow \mathrm{Bu}^{t} \mathrm{SBR}_{2}+\mathrm{R} \cdot
\end{aligned}
$$

Under similar conditions dimethyl disulphide and diphenyl disulphide establish a chain reaction because the displaced radical $R \cdot$ can regenerate the alkylthiyl radical by attack on the disulphide, e.g. (cf. ref. 17).

$$
\mathrm{R} \cdot+\mathrm{PhSSPh} \rightarrow \mathrm{RSPh}+\mathrm{PhS} \text {. }
$$

Similarly, thiols react with an alkylborane by a chain process, to give alkane and alkylthioborane, the alkylthiyl radical being regenerated by attack of the alkyl radical at the hydrogen of the thiol, e.g. equations (23) and (24)

$$
\begin{aligned}
& \mathrm{PhS} \cdot+\mathrm{BBu}_{3} \rightarrow \mathrm{PhSBBu}_{2}+\mathrm{Bu} \cdot \\
& \mathrm{Bu} \cdot+\mathrm{HSPh} \rightarrow \mathrm{BuH}+\cdot \mathrm{SPh}
\end{aligned}
$$

Relative values for the rate constants of the reactions of different boranes have been determined by competition reactions, and have been put on an absolute basis by comparison with the rate of addition of the butylthiyl radical to 1 -octene ${ }^{17}$.

\section{DIALKYLAMINYL RADICALS}

Photolysis of tetramethyltetrazene in the presence of a trialkylborane provides the nitrogen equivalent of the reactions of di-t-butyl peroxide, and di-t-butyl disulphide $:$ if the reaction is carried out in an e.s.r. cavity, the spec- 
trum of the displaced alkyl radical can be observed ${ }^{18}$.

$$
\begin{aligned}
& \mathrm{Me}_{2} \mathrm{NN}=\mathrm{NNMe}_{2} \stackrel{h \prime}{\longrightarrow} \mathrm{N}_{2}+2 \mathrm{Me}_{2} \mathrm{~N} \cdot \\
& \mathrm{Me}_{2} \mathrm{~N} \cdot+\mathrm{BR}_{3} \longrightarrow \mathrm{Me}_{2} \mathrm{NBR}_{2}+\mathrm{R} \cdot
\end{aligned}
$$

Dimethylchloramine provides the nitrogen equivalent of the reaction of an alkyl hypochlorite. Homolytic substitution by the dimethylaminyl radical at the boron centre displaces the alkyl radical, which in turn attacks the chloroamine to regenerate the dimethylaminyl radical, and the products are the aminoborane and the alkyl chloride, by reactions (27) and (28).

$$
\begin{aligned}
& \mathrm{Me}_{2} \mathrm{~N} \cdot+\mathrm{BR}_{3} \rightarrow \mathrm{Me}_{2} \mathrm{NBR}_{2}+\mathrm{R} \cdot \\
& \mathrm{R} \cdot+\mathrm{ClNMe}_{2} \rightarrow \mathrm{RCl}+\cdot \mathrm{NMe}_{2}
\end{aligned}
$$

This process is in competition with a parallel heterolytic reaction which leads to the formation of chloroborane and tertiary amine.

$$
\mathrm{Me}_{2} \mathrm{NCl}+\mathrm{BBu}_{3} \rightarrow \mathrm{Me}_{2} \mathrm{NBu}+\mathrm{Bu}_{2} \mathrm{BCl}
$$

Further cleavage of two remaining alkyl-boron bonds then takes wholly the homolytic route. The relative $\mathrm{S}_{\mathrm{H}} 2$ reactivities of different boranes have been obtained by competition experiments, but absolute values for the rate constants are not yet available ${ }^{20}$.

\section{KETONE TRIPLETS}

Ketone triplets show many of the reactions of alkoxyl radicals, and this extends to their reactions with organometallic compounds. If, for example, acetone is photo-excited in the presence of tributylborane in an e.s.r. cavity, the superimposed spectra of the ketyl radical and the displaced alkyl radical can be observed, and the products

$$
\mathrm{Me}_{2} \mathrm{CO}^{\mathrm{T}}+\mathrm{BBu}_{3} \rightarrow \mathrm{Me}_{2} \mathrm{COBBu} u_{2}+\mathrm{Bu} \cdot
$$

result from the self-combination and cross-combination of these radicals. By causing the borane to compete with a triplet quencher for reaction with the triplet, the rate of the $S_{H} 2$ process can be determined ${ }^{21}$.

Many other reactions of boranes and other organometallic compounds with reagents in their excited states appear to be possible : this is a major field which as yet has heen hardly touched.

\section{KINETICS AND MECHANISMS}

A selection of rate constants for the $\mathrm{S}_{\mathrm{H}} 2$ reaction of radicals at the boron centre in organoboranes is given in Table 1 ; a more complete compilation can be found in ref. 2 .

These data show that the reactions of organoboranes, and particularly of the trialkylboranes, towards the radicals listed are very fast. Both kinetic and thermodynamic factors contribute to this.

First, the boron centre in trialkylboranes has a readily accessible $2 p$ orbital to accommodate the attacking radical and form the 4-coordinate 
Table 1. Rate constants $\left(\mathrm{M}^{-1} \mathrm{~s}^{-1}\right)$ for the $\mathrm{S}_{\mathrm{H}^{2}}$ reactions $\mathrm{X} \cdot+\mathrm{B}-\mathrm{R} \rightarrow \mathrm{X}-\mathrm{B}^{\prime}+\mathrm{R}$.

\begin{tabular}{|c|c|c|c|c|}
\hline Organoborane & $\begin{array}{c}\text { ROO } \\
\left(30^{\circ}\right)\end{array}$ & $\begin{array}{l}\mathrm{Bu} \mathrm{C}^{+} \mathrm{O}^{\circ} \\
\left(40^{\circ}\right)\end{array}$ & $\begin{array}{l}\text { Bu'S. } \\
\left(50^{\circ}\right)\end{array}$ & $\begin{array}{c}\mathrm{Me}_{2} \mathrm{CO}^{\mathrm{T}} \\
\left(20^{\circ}\right)\end{array}$ \\
\hline $\begin{array}{l}\mathrm{Bu}_{3}^{\mathrm{n}} \mathrm{B} \\
\mathrm{Bu}_{3}^{i} \mathrm{~B} \\
\mathrm{Bu}_{3}^{\mathrm{s}} \\
\mathrm{Pe}_{3}^{\mathrm{nec}} \mathrm{B}\end{array}$ & $\begin{array}{l}2 \times 10^{6} \\
8 \times 10^{4}\end{array}$ & $\begin{array}{l}1 \times 10^{7} \\
3 \times 10^{5} \\
4 \times 10^{5} \\
4 \times 10^{4}\end{array}$ & $\begin{array}{l}5 \times 10^{7} \\
5 \times 10^{6} \\
6 \times 10^{6}\end{array}$ & $\begin{array}{l}7 \times 10^{6} \\
8 \times 10^{4} \\
1 \times 10^{4}\end{array}$ \\
\hline $\begin{array}{l}\left(\mathrm{PhCH}_{2}\right)_{3} \mathrm{~B} \\
\mathrm{Ph}_{3} \mathrm{~B} \\
\left(\mathrm{Bu}^{\mathrm{n}} \mathrm{BO}\right)_{3} \\
\left(\mathrm{Bu}^{5} \mathrm{BO}\right)_{3} \\
\left(\mathrm{Bu}^{t} \mathrm{BO}\right)_{3} \\
\left(\mathrm{PhCH}_{2} \mathrm{BO}\right)_{3}\end{array}$ & $\begin{array}{l}5 \times 10^{6} \\
1 \times 10^{3} \\
5 \times 10^{4} \\
3 \times 10^{4} \\
1 \times 10^{6}\end{array}$ & $\begin{array}{l}2 \times 10^{7} \\
1 \times 10^{7} \\
3 \times 10^{5} \\
6 \times 10^{5} \\
3 \times 10^{6}\end{array}$ & & \\
\hline
\end{tabular}

transition state. The reactivity of the boroxines is lower [e.g. $k$ for alkylperoxydealkylation, $\left.\mathrm{Bu}_{3}^{\mathrm{n}} \mathrm{B}, 2 \times 10^{6} ;\left(\mathrm{Bu}^{\mathrm{n}} \mathrm{BO}\right)_{3}, 1 \times 10^{3} \mathrm{M}^{-1} \mathrm{~s}^{-1}\right]$ because the $\mathrm{p}_{\pi}-\mathrm{p}_{\pi}$ bonding from oxygen to boron has to be disrupted when the transition state is formed. The amine complexes of the boranes, in which this p orbital is fully utilized in bonding, react only insofar as they dissociate.

Second, the B-C bond which is being broken is rather weak, whereas the electronegative attacking radical can form a strong bond to the boron centre. For example, if the approximate bond energy terms are taken to be $\bar{D}(\mathrm{~B}-\mathrm{C})=$ $83, \bar{D}(\mathrm{~B}-\mathrm{O})=125, \bar{D}(\mathrm{H}-\mathrm{C})=99$, and $\bar{D}(\mathrm{H}-\mathrm{O})=110 \mathrm{kcal} \mathrm{mole}^{-1}$, alkoxydealkylation at boron will be exothermic by $42 \mathrm{kcal} \mathrm{mole}^{-1}$, but at hydrogen by only $11 \mathrm{kcal} \mathrm{mole}^{-1}$.

These two factors combine to provide a reaction path of lower activation energy ( $0-6 \mathrm{kcal} \mathrm{mole}^{-1}$ for the alkoxydealkylation of organoboranes), and a very rapid reaction.

The importance of the nature of the leaving group shows up in the reactions of the boroxines. The trialkylboranes are so reactive that the transition state lies only a short distance along the reaction coordinate where there is little stretching of the $\mathrm{B}-\mathrm{C}$ bond, and any resonance stabilization of the departing group is unimportant (e.g. $k$ for alkylperoxydealkylation, $\mathrm{Bu}_{3}^{\mathrm{n}} \mathrm{B} 2 \times 10^{6}$, $\left.\left(\mathrm{PhCH}_{2}\right)_{3} \mathrm{~B} 5 \times 10^{6}\right)$. In the less reactive boroxines, the $\mathrm{B}-\mathrm{C}$ bond is more extended in the transition state, and the contribution of benzylic resonance in lowering the activation energy becomes apparent $[k$ for alkylperoxydealkylation, $\left.\left.\left(\mathrm{Bu}^{\mathrm{n}} \mathrm{BO}\right)_{3}\right] \times 10^{3},\left(\mathrm{PhCH}_{2} \mathrm{BO}\right)_{3} 1 \times 10^{6} \mathrm{M}^{-1} \mathrm{~s}^{-1}\right]$.

It is interesting that triphenylborane shows the same $\mathrm{S}_{\mathrm{H}} 2$ reactivity as tributylborane towards $t$-butoxyl radicals $\left(k=1 \times 10^{7} \mathrm{M}^{-1} \mathrm{~s}^{-1}\right)^{22}$. Free radicals normally attack benzene itself at a ring-carbon centre, but the ease of substitution at a boron centre diverts attack in the phenylborane to the extracyclic atom.

Steric effects on the reactions can also be identified. These may account for the fact that tri-s-butylborane is generally less reactive than tri- $n$-butylborane, although the stability of the displaced radical would suggest the opposite sequence, and they are most obvious in the $t$-butoxydealkylation of tri- 
neopentylborane $\left(k 4 \times 10^{4}\right)$ which is 250 times less reactive than tri- $n$ butylborane $\left(k 1 \times 10^{7}\right)$.

\section{REFERENCES}

${ }^{1}$ K. U. Ingold and B. P. Roberts, Free Radical Substitution Reactions, Interscience : New York (1971).

2 A. G. Davies and B. P. Roberts, Free Radicals, Vol. 1, Chap. 10. Ed. J. Kochi, Wiley: New York (1973).

3 D. S. Matteson, J. Org. Chem. 29, 3399 (1964).

${ }^{4}$ A. G. Davies and B. P. Roberts, Chem. Commun. 298 (1966); J. Chem. Soc. (B), 17 (1967).

5 A. G. Davies, Organic Peroxides, Vol. II, Chap. 4. Ed. D. Swern, Wiley: New York (1971).

${ }^{6}$ C. Walling and S. A. Buckler, J. Amer. Chem. Soc. 77, 6039 (1955).

${ }^{7}$ M. H. Abraham and A. G. Davies, J. Chem. Soc. 429 (1959).

8 T. D. Parsons, M. B. Silverman and D. M. Ritter, J. Amer. Chem. Soc. 79, 5091 (1957).

9 D. S. Matteson and R. A. Bowie, J. Amer. Chem. Soc. 87, 2587 (1965).

10 (a) A. G. Davies and B. P. Roberts, J. Chem. Soc. (B), 1074 (1968).

(b) P. G. Allies and P. B. Brindley, J. Chem. Soc. 1126(1969).

11 K. U. Ingold, Chem. Commun. 911 (1969).

A. G. Davies, K. U. Ingold, B. P. Roberts and R. Tudor, J. Chem. Soc. (B), 698 (1971).

S. Korcek, G. B. Watts and K. U. Ingold, J. Chem. Soc., Perkin II, 242 (1972).

12 A. G. Davies and B. P. Roberts, Chem. Commun. 699 (1969).

J. Organometallic Chem. 19, P17 (1969).

13 P. J. Krusic and J. K. Kochi, J. Amer. Chem. Soc. 91, 3942 (1969).

J. K. Kochi and P. J. Krusic, J. Amer. Chem. Soc. 91, 3944 (1969); 94, 6033 (1972).

14 A. G. Davies, D. Griller and B. P. Roberts, J. Chem. Soc. (B), 1823 (1971).

15 A. G. Davies, T. Maki and B. P. Roberts, J. Chem. Soc., Perkin II, 744 (1972).

${ }^{16}$ H. C. Brown and M. M. Midland, Angew. Chem. Internat. Edn, 11, 692 (1972).

17 A. G. Davies and B. P. Roberts, J. Chem. Soc. (B), 1830 (1971).

18 A. G. Davies, S. C. W. Hook and B. P. Roberts, J. Organometallic Chem. 22, 37 (1970).

19 A. G. Davies, S. C. W. Hook and B. P. Roberts, J. Organometallic Chem. 23, 11 (1970).

${ }^{20}$ K. G. Foot, unpublished work.

21 A. G. Davies, B. P. Roberts and J. C. Scaiano, J. Chem. Soc. (B), 2172 (1971).

A. G. Davies and J. C. Scaiano, J. Chem. Soc., Perkin II, 2234 (1972). 